\title{
Feasibility of total laparoscopic hysterectomy as a day care procedure
}

\section{Chitra Thyagaraju, Rajesh Modi*}

\author{
${ }^{1}$ Department of Obstetrics \& Gynaecology, Jawaharlal Institute of Post-Graduate Medical Education and Research \\ Puducherry, India \\ ${ }^{2}$ Director \& Endoscopy Surgeon, Akola Endoscopy Centre, Akola, Maharashtra, India
}

Received: 11 August 2014

Accepted: 19 August 2014

\author{
*Correspondence: \\ Dr. Rajesh Modi, \\ E-mail: drrajeshmodi@gmail.com
}

(C) 2014 Thyagaraju $\mathrm{C}$ et al. This is an open-access article distributed under the terms of the Creative Commons Attribution Non-Commercial License, which permits unrestricted non-commercial use, distribution, and reproduction in any medium, provided the original work is properly cited.

\begin{abstract}
Background: Aim of current study was to evaluate the feasibility of Total Laparoscopic Hysterectomy (TLH) as a day care procedure and compare its outcome in relation to uterine size.

Methods: A retrospective cohort study of all patients who underwent total laparoscopic hysterectomy for benign pathologies between March 2010 to April 2011 at Akola endoscopy centre, Akola, Maharashtra, were included in the study. Demographic and surgical data like estimated blood loss, operating time, rate of complications were analysed. Re-admission and re-operation rate were also analysed. A comparison between uterine height $<12$ weeks and uterine height $>12$ weeks were performed. Analysis was performed by SPSS version 15 and chi-square test.

Results: The mean age of the patients was 43.05 years (range 32-66 years). The mean parity was 2.1 (range 1-4). The mean operating time was 52.83 minutes (range 40-115), which varied according to the uterine sizes, with a mean 52.4 (range 40-68) for smaller uterus $<12$ weeks and for a uterus $>12$ weeks mean operative time was 68.23 (range 55-115 minutes) which was statistically significant $(\mathrm{P}=0.000)$. The mean estimated blood loss was significantly less in patients with small uteri at $40.20 \mathrm{ml}$ (range 15-80) than in patients with uterus $>12$ weeks, at $62.50 \mathrm{ml}$ (range 40 250). ( $\mathrm{P}=0.001)$. There were no major intraoperative/post-operative complications. Minor post-operative complication rate was 7\%. The Mean hospital stay was 8.2 hours (5 hours - 12 hours).The re-admission rate was $4 \%$.

Conclusions: These preliminary data suggests that day care laparoscopic hysterectomy is feasible, safe with greater efficacy; however the skill of the surgeon matters. With better understanding of the technique, the advent of better anaesthetic agent, increased surgical experience and patient awareness has helped Day care surgery in to an art and which can be considered as a speciality
\end{abstract}

Keywords: Day care laparoscopic hysterectomy

\section{INTRODUCTION}

Laparoscopic surgery from 1975-1988 was essentially organ preserving surgery. The whole attitude towards laparoscopy surgery changed when Harry Riech performed first case of laparoscopy hysterectomy in 1989 but was criticized because of prolonged operative time which were overcome by adaptations in techniques (LAVH, LH, TLH). ${ }^{1}$
The concept of "Day care surgery" or "walk-in-walk-out" surgery originated in some hospitals in the united states as far back as 1962. The opening of Surgicenter in Arizona (USA) in 1971 has pioneered the modern day approach. Surgery in an out-patient setting has become a global trend and is expanding through-out the world. It is estimated that by 2020, $75 \%$ of all surgical operations will be carried out in ambulatory surgery centers. 
In India, the concept of day care surgery accounts to $20 \%$ of all surgical procedures, laparoscopic hysterectomy as a day care procedure is currently in its infancy stage. Inpatient facilities are expensive, inconvenient and less than savoury to most patients. Technological advances over the last two decades have helped to address this gap. A large number of surgeries can now be performed without the patient having to be admitted at all. The advantage to the consumer will be high satisfaction, improved cosmetic result, better ambience, convenient schedule, more organised and friendlier staff and lesser incidence of hospital acquired infections and ileus.

The success of day care surgery depends on proper selection of cases, separate day care centre, minimal use of parenteral opioids, use of simple oral analgesics and wider use of propofol as an induction agent which provides superior recovery from anaesthesia. ${ }^{2}$

The aim of our study was to evaluate the feasibility of Total Laparoscopic Hysterectomy (TLH) as a day care procedure and compare its outcome in relation to uterine size. Our study is the first single centre and single surgeon series on day care laparoscopic hysterectomy.

\section{METHODS}

\section{Design}

Retrospective cohort study

\section{Intervention: Total laparoscopic hysterectomy (TLH)}

Clinical records of patients $(\mathrm{N}=212)$ who had undergone Total laparoscopic hysterectomy for a benign pathology at Akola endoscopy center (Akola, Maharashtra, India) between April 2011 to March 2012 were retrieved. Most of these patients had primary medical management for their pathology at their places. They were referred to our endoscopy center when medical management failed and when patient insisted on laparoscopy hysterectomy. Out of this, 12 patients clinical records and surgery details were inaccurate and were excluded. Patients with cancerous lesions and patients with genital prolapse and / or stress urinary incontinence were excluded from the study. Patients were admitted on the day of surgery with expected discharge on the same day. The retrograde observational study was approved by centre ethical committee.

Variables studied included age, parity, symptoms, diagnosis, the indication for intervention, concomitant procedures, previous surgeries.

We also included estimated blood loss, operating time, suture material used and uterine size in weeks which was divided in to 2 categories [ $<12$ weeks (group 1 ) and more than 12 weeks (group 2)] and compared the variables in relation to uterine size.
Intra-operative complications were categorised as none, bladder / ureter / bowel / vessel injury. Post-operative complications included fever, ileus, nausea and vomiting, urinary tract infections, secondary haemorrhage. We also looked for patients who were re-admitted within 30 days of discharge and those who returned to operating room.

Statistical analysis was done using SPSS version17 and chi-square test.

The total laparoscopic hysterectomy was performed using the same technique in all subjects by the single surgeon, with a senior/junior staff member usually assisting. The data on all surgical procedures was obtained from our data base record book.

Pre-operatively, patient is advised liquid diet from $3 \mathrm{pm}$ on previous day and for bowel preparation 2 tablets of dulcolax to be taken at $7 \mathrm{pm}$ along with one tablet of ranitidine $(300 \mathrm{mg})$ and alprazolam $(0.5 \mathrm{mg})$. One tablet of betadine vaginal pessary to be inserted before going to bed. Patient was admitted to the centre on the morning of surgery nil by mouth.

Anaesthesia protocol: On table, Injection clonidine 1.5 $\mu \mathrm{g} / \mathrm{kg} / \mathrm{BW}$ IV slowly. All patients were induced for general anaesthesia with propofol, $3 \mathrm{mg}$ midazolam + fentanyl 2-3 $\mu \mathrm{g} / \mathrm{kg} / \mathrm{BW}+$ glycopyrrolate. Inj. dexamethasone $8 \mathrm{mg}$ given and $1 \mathrm{gm}$ cefotaxime given at induction. Laryngeal mask (LMA) is used in place of endo-tracheal tube. This avoids trauma to the vocal cord and also reduces post-operative throat infection. Maintenance by atracurium + air + sevoflurane + propofol drip. Ondansetron $4 \mathrm{ml}$ given during reversal to prevent nausea and vomiting.

Position: patient was kept in supine position with knee and hip in semi-flexion. This helped to prevent backache.

\section{Operative technique}

A video laparoscopy technique with a single chip camera and a television monitor was placed at patient's feet. A $10 \mathrm{~mm} 30$ degree laparoscope through the supra-umbilical port followed by three ancillary $5 \mathrm{~mm}$ ports ( two on surgeon's side and one on other side)was inserted after creating pneumoperitoneum (CO 2-14 mmHg) lateral to inferior epigastric vessels. No intra-uterine/vaginal manipulator was used, but a myoma screw was used laparoscopically for uterine mobilisation. Bi-polar cautery system was the instrument used for coagulation and haemostasis.

After careful inspection of abdomen and pelvis, uterus was pulled up with the help of myoma screw introduced at fundus and held by assistant for traction. Bi-polar electro-cauterization of the fallopian tubes, ovarian ligament and round ligament was performed and cut. The anterior leaf of broad ligament was dissected up to uterovesical fold, bladder flap elevated and bladder pushed 
down gently from cervical surface. Posteriorly the peritoneum was dissected till the utero-sacral ligament detachment, as a result ureter is pushed more laterally, this reduces risk of ureter injury. Uterine vessel were skeletonised, cauterised with bi-polar and cut with scissors. Dissection continued downwards medial to uterine vessels, cauterising and cutting the cardinal ligaments. Vesico-cervical fascia below the isthmus level was dissected from lateral to medial side and pushed downwards. This plane of dissection provides an anatomical landmark for opening of the vault anteriorly and avoiding accidental injury to bladder by cautery. Dissection was done on opposite side in similar manner. Vagina was opened postero-laterally below the attachment of utero-sacral ligament and $1 \mathrm{~cm}$ above the cervical os on either side. Entire vault is cut circumferentially with scissors, using bi-polar where necessary.

Uterus was morcellated using laparoscopic morcellator, if necessary and pulled out of vagina. The vaginal cuff was sutured laparoscopically using vicryl no.2.0/ vicryl rapide. Under saline examination was done to check haemostasis and approximately $800 \mathrm{ml}$ of normal saline was left in peritoneal cavity. As an analgesic, $10 \mathrm{ml}$ sensocaine $(0.5 \%)$ was instilled intra-peritoneally, $10 \mathrm{ml}$ infiltrated at all port incision sites. Diclofenac suppository was kept per rectally at end of the procedure. No intravenous fluid administration, indwelling Foley's catheter or pelvic drain was used post operatively in our procedure.

Post-operatively, patient received nasal oxygen along with monitoring of vitals, pulse oximetry for 2 hours. Patient was mobilised 2-3hrs after surgery and allowed to go to pass urine and later started with liquid diet. Full diet was started $4-5$ hours after surgery and discharged 8-10 hours postoperatively. The operating surgeon and assistant staff were available for the patient at any time after discharge.

\section{RESULTS}

A total of 200 patients underwent total laparoscopic hysterectomy and all the procedures were successfully completed by laparoscopy.

Table 1: Demographic characteristics of the patient $(n=200)$.

\begin{tabular}{|lllll|} 
& Total $(\mathbf{n = 2 0 0 )}$ & $\begin{array}{l}\text { Uterine size <12 } \\
\text { weeks (Group I) } \\
(\mathrm{N}=168)\end{array}$ & $\begin{array}{l}\text { Uterine size }>12 \\
\text { weeks (Group II) } \\
(\mathbf{N}=32)\end{array}$ & P value \\
\hline Mean age & $43.05(22-66)$ & $43.05(30-62)$ & $42.05(32-58)$ & $\mathrm{P}=0.026$ \\
\hline Mean parity & $2.14(1-4)$ & $2.05(1-4)$ & $2.11(1-4)$ & $\mathrm{P}=0.166$ \\
\hline Post-menopausal & $22(11 \%)$ & $21(12.5 \%)$ & $1(3.1 \%)$ & $\mathrm{P}=0.318$ \\
\hline Mean uterine size & $8.2(6-24)$ & $8.2(6-12)$ & $16.2(12-26)$ & $\begin{array}{l}\mathrm{P}=0.027 \\
\text { Wignificant }\end{array}$ \\
\hline Women with previous LSCS & $32(16 \%)$ & $19(11.3 \%)$ & $11(34.3 \%)$ & - \\
\hline Women with previous laparotomy & $13(6.5 \%)$ & $10(5.9 \%)$ & $3(9.3 \%)$ & - \\
\hline Women with previous laparoscopy & $6(3 \%)$ & $4(2.4 \%)$ & $2(6.5 \%)$ & \\
\hline
\end{tabular}

Table 2: Intra-operative outcome in relation to uterine size.

\begin{tabular}{|c|c|c|c|c|}
\hline & Total $(\mathrm{N}=\mathbf{2 0 0})$ & $\begin{array}{l}\text { Uterine size <12 } \\
\text { weeks (Group I) } \\
(\mathrm{N}=168)\end{array}$ & $\begin{array}{l}\text { Uterine size }>12 \\
\text { weeks (Group II) } \\
(\mathbf{N}=32)\end{array}$ & $P$ value \\
\hline TLH & $147(73.5 \%)$ & $127(75.6 \%)$ & $20(62 \%)$ & \\
\hline $\mathrm{TLH}+\mathrm{BSO}$ & $12(6 \%)$ & $12(7.14 \%)$ & 0 & \\
\hline TLH + USO & $29(14.5 \%)$ & $21(12.5 \%)$ & $8(25 \%)$ & \\
\hline TLH + Hernia repair & $7(3.5 \%)$ & $4(2.4 \%)$ & $3(9.4 \%)$ & \\
\hline TLH + Rt. salpingectomy & $5(2.5 \%)$ & $4(2.4 \%)$ & $1(3.1 \%)$ & \\
\hline Adhesions & $66(33 \%)$ & $46(23 \%)$ & $20(10 \%)$ & $\begin{array}{l}\mathrm{P}=0.004 \\
\text { Significant }\end{array}$ \\
\hline Operative time (minutes) & $\begin{array}{l}52.83 \text { minutes } \\
(40-115)\end{array}$ & $\begin{array}{l}52.4 \text { minutes } \\
(40-68)\end{array}$ & $\begin{array}{l}68.23 \text { minutes } \\
(55-115)\end{array}$ & $\begin{array}{l}\mathrm{P}=0.001 \\
\text { Highly } \\
\text { significant }\end{array}$ \\
\hline Estimated blood loss (ml) & $\begin{array}{l}40.50 \mathrm{ml} \\
(15-250 \mathrm{ml})\end{array}$ & $\begin{array}{l}40.20 \mathrm{ml} \\
(15-80 \mathrm{ml})\end{array}$ & $\begin{array}{l}62.50 \\
(40-250 \mathrm{ml})\end{array}$ & $\begin{array}{l}\mathrm{P}=0.001 \\
\text { Highly } \\
\text { significant }\end{array}$ \\
\hline
\end{tabular}


The mean age of the patient was 43.05 years (32-66 years). The mean parity was 2.1 (range 1-4). The most common symptom was menorrhagia (47\%) followed by postmenopausal bleeding $(11 \%)$. The most common indication for the TLH was dysfunctional uterine bleeding $(47 \%)$ followed by fibroid uterus $(44.5 \%)$ (Table 2).

The most common concomitant procedure was unilateral salpingo-oophorectomy in 29 women (14.5\%) (Table 3). Ovarian pathology was seen in 38 women $(19 \%)$, out of which 11 cases were diagnosed preoperatively. The benign cyst seen in 32 women, out of which 3 women had cyst aspiration because of its small size, the chocolate cyst was seen in 4 women, haemorrhagic cyst in 2 women, 1 case of dermoid.

Table 3: Indications for TLH.

\begin{tabular}{|lc|}
\hline Indications for TLH \\
\hline Dysfunctional uterine bleeding & $94(55 \%)$ \\
\hline Fibroid & $89(44 \%)$ \\
\hline Benign ovarian cyst & $11(5 \%)$ \\
\hline Menorrhagia & $6(3 \%)$ \\
\hline
\end{tabular}

Mean uterine size was 8.4 weeks (6-26 weeks), with 168 patients $(84 \%)$ having uterine size $<12$ weeks and 32 patients $(16 \%)$ had uterine size $>12$ weeks, out of which 4 patients $(2 \%)$ had uterine size $>20$ weeks. The upper limit of uterine size was 26 weeks. 51 women $(25.5 \%)$ had previous pelvic surgeries; with $8.5 \%$ women had previous 2 LSCS (Table 4). Age, parity, previous history caesarean/laparotomy and post-menopausal status were significantly greater in patients with uterine size $<12$ weeks and was not statistically significant.

Adhesiolysis was performed in 55 women (27.5\%), out of which 51 women had previous pelvic surgeries, 4 had intra-operative features of PID .Bladder was adherent in almost all cases of previous LSCS., bowel adhesions in $1 \%$ cases, omental adhesions in $22 \%$ of cases. The mean operative time for TLH with adhesiolysis was 60.4 minutes (Table 1). There was no difference between proportions of duration of surgery among the adhesions.

The intra-operative outcomes are summarized in Table 4.

Table 4: Post-operative complications $(\mathrm{N}=200)$.

\begin{tabular}{|ll|}
\hline Post-operative complications & \\
\hline Febrile morbidity & 5 \\
\hline Wound infection & 1 \\
\hline Urinary tract infection & 0 \\
\hline Nausea and vomiting & 4 \\
\hline Vault haematoma & 1 \\
\hline No. of patients who stayed overnight & 3 \\
\hline Readmission & 7 \\
\hline No. of patient with significant haemorrhage & 27 \\
\hline No. of patients requiring blood transfusion & 3 \\
\hline
\end{tabular}

The mean operating time was 52.83 minutes (range 40$115)$, which varied according to the uterine sizes, with a mean 52.4 (range 40-68) for smaller uterus <12 weeks and for a uterus $>12$ weeks, mean operative time was 68.23 (range 55-115 minutes) ( $\mathrm{P}<0.001)$. The duration of surgery was more than 90 minutes in 10 women $(5 \%)$, this is because of larger uterus requiring morcellation and concomitant herniorraphy. Operating time remained significantly longer for patients with extensive adhesiolysis, larger uterus and hernia repair which were statistically significant.

The mean estimated blood loss for all patients was 40.50 $\mathrm{ml}(15-250 \mathrm{ml})$, and was significantly less in patients with small uteri with mean $40.20 \mathrm{ml}(15-80 \mathrm{ml})$ than in patients with uterus $>12$ weeks with mean 62.50 (40-250 $\mathrm{ml})(\mathrm{P}<0.001)$ which was statistically significant. 9 patients $(4.5 \%)$ had blood loss more than $200 \mathrm{ml}$, mainly because of back flow from large uterus, extensive adhesiolysis which also resulted in longer operative time. Mean hospital stay (hours) was 8.2 (5 hours - 12 hours) for all patients except 3 patients $(1.5 \%)$ who stayed overnight for social reasons.

There were no major intra-operative/post-operative complications in our study. 14 patients $(7 \%)$ experienced post-operative complications. 3 patients (1.5\%) developed pyrexia $>37.5$ degree on first post-operative day, who needed readmission for intravenous antibiotics, 2 patient had wound infection and 4 patients had nausea and vomiting which were managed conservatively. There were 5 patients $(2.5 \%)$ with significant secondary haemorrhage who reported on second and third week post-operatively, 3 patients $(1.5 \%)$ received blood transfusion, 1 patient had vault infection which needed secondary suturing after antibiotics and one patient was managed only with antibiotics. There were no cases of urinary tract infection mainly because of noncauterisation of bladder post-operatively and early ambulation. The re-admission rate was $4 \%$.

45 patients $(22.5 \%)$ patients had mild febrile response on first post-operative day. This is seen quite frequently and also expected as TLH involves coagulation and cutting of the tissues which results in some dead tissue and some charred tissue which remains inside. Acute inflammatory response of the body to clear this charring tissue may manifest as a febrile response.

None of the variables studied had a significant association with post-operative complications. These included age $(\mathrm{P}<0.0 .39)$, parity $(\mathrm{P}<0.09)$, concomitant procedures $(\mathrm{P}<0.245)$, adhesiolysis $(\mathrm{P}<0.502)$, Uterine size $<12$ weeks $(\mathrm{P}<0.089)$, uterine size $>12$ weeks $(\mathrm{P}$ $<0.0113)$, blood loss $(\mathrm{P}<0.312)$.

\section{DISCUSSION}

We conducted a retrospective cohort study of 200 patients to evaluate the feasibility of total laparoscopic 
hysterectomy as a day care procedure and its outcome in relation to size of uterus.

Day care surgery or ambulatory gynaec care is only possible with help of minimally invasive procedures like laparoscopy and hysteroscopy. Since the time first laparoscopic hysterectomy was described by Reich et al. (1989), the laparoscopic procedure has become procedure of choice in gynaecologic surgery and many authors have reported different technique for performing this procedure. $^{3-6}$ Our experience showed that TLH as a day care procedure could be easily performed in a variety of patients requiring hysterectomy. The advantage of Total laparoscopic hysterectomy to the patient will be improved cosmetic result, less post-operative pain, less discomfort, shorter hospital stay, early recovery ${ }^{7}$ and lesser incidence of nosocomial infections.

The mean age of the patient (43.05), parity (2.1), demographic characteristics are similar to studies done by other authors. $^{13,14}$

The most common indication to perform TLH in our study was dysfunctional uterine bleeding (47\%) which was similar to indication reported by van Evert et al. ${ }^{12}$ but in contrast to other studies where fibroid uterus was the most commonest indication for TLH. ${ }^{8-11}$ The mean uterine size in our study was $8.4 \mathrm{wks}$ which was similar to study done by O'Hanlan et al., ' where the mean uterine weight was 146 (14-3131 gm), and was smaller in size in comparison to study by Kapoor Nisha et al., ${ }^{15}$ as fibroid uterus was most common indication for TLH in their study.

Adhesiolysis was done in $27.5 \%$ patients which were similar Kapoor Nisha et al. ${ }^{15}$ The explanation for this similarity is presence of high incidence of previous pelvic surgeries in both the studies (25.5\% in similar to $28.6 \%)$. There is no difference between the proportions of duration of surgery among the adhesions. The omental adhesions were most commonly encountered in patients with previous pelvic surgeries which did not add on to extra time.

TLH with concomitant procedures was done in $26 \%$ of patients which is much lesser than other studies. ${ }^{9,15}$ O'Hanalan et al. in their study removed both the ovaries in almost $91.4 \%$ in contrast to $6 \%$ in our study as we retain the ovaries in all patients irrespective $s$ of the age of the patient unless it is pathological or with positive family history of malignancy. These procedures did not affect the duration of surgeries.

Mean skin-to-skin operative time was 52.83 (range 40115 minutes) which was similar to Payne et al. ${ }^{17}$ and was shorter in comparison to other studies..$^{9,13,14,16}$ This difference may be due to increasing experience of surgeon and different authors report their series at different stages of learning curve. The operating time will decrease with increasing surgeon's skill, advanced cautery system/technique, use of bi-polar or and harmonic scalpel.

O'Hanlan et al. ${ }^{9}$ reported median duration of surgery in 720 patients with uteri $<250 \mathrm{gm}$ at 97 minutes and 26 patients with uterine size $>250 \mathrm{gm}$ at 120 minutes which was longer than our study. Payne et al. ${ }^{18}$ report median robotic operating time in 200 patients with larger uteri $>250 \mathrm{gm}$ and $500 \mathrm{gm}$ at 126 minutes, which was much longer than our study for the same uterine size in weeks (mean 68.23 minutes). Laparoscopic approach to larger myoma uterus may be most economical, feasible, universally available, minimally invasive option than robotically assisted hysterectomy because of the cost, special training, maintenance of robotic machine, as well as cost of downtime because of unanticipated repairs and limits the use of robotics. Bigger size uterus did not affect the outcome of day care surgery, the patient did not have any complications and was discharged same day, it shows that even bigger size uterus can be done as day care surgery.

Some authors. ${ }^{16,19}$ reported that operative time is also affected by adhesions, increased uterine size and obesity in contrast to our study.

The mean estimated blood loss was 40.50ml (15-200ml), which was comparable to mean $50 \mathrm{ml}$ reported by studies $^{9,17}$ but was much lesser than other studies. ${ }^{10,11,13,21}$ The variations in blood loss and operative time reported in the different studies can be explained by difference in mean uterine size, concomitant procedures, stage of learning curve and technique. ${ }^{15}$

Mean total length of hospital stay was 8.2 hours, longer than Taylor et al. ${ }^{20}$ but was much shorter in comparison to other studies practising day care surgery. ${ }^{14,22,23}$ Thiel et al. ${ }^{13}$ reported mean post-operative stay of 5.9 hours and Morrison et al. ${ }^{14}$ reported 6 hours 79 minutes, the difference may be because only post-operative stay was calculated in these studies. In our study, only 3 patients $(1.5 \%)$ stayed overnight for social reasons in comparison to other studies ${ }^{4,13,14}$ where $>5 \%$ stayed overnight for various medical and social reasons.

Effective post-operative pain management and our protocol of propofol infusion along with dexamethasone and ondansetron as prophylactic antiemetic was found to be quite effective in combating peri-operative nausea and vomiting which is a big problem following day care surgery. As bowel motility is not hampered intraoperatively, patient easily tolerates food after three hours and is fit for discharge after 6-8 hours of surgery.

There was no major intra-operative or post-operative complications in our study similar to other studies. ${ }^{14,17,23}$ The reason may be skill of the surgeon who are experienced more than 10 years in doing the TLH technique. This study evaluated the output from the single experienced surgeon. Post-operative complications rate was $7 \%$ which was less than other studies. ${ }^{4,21,24}$ 
Re-admission rate was $4.0 \%$ in our study similar to $4.1 \%$ reported by other study. ${ }^{11}$ The main reason for readmission was febrile morbidity and secondary haemorrhage, 3 patients required blood transfusion. No intra-operative factors contributed for secondary haemorrhage or febrile morbidity.

Day care surgery has been a great success at our centre because of independent small unit with dedicated facilities, function adapted design, full time dedicated staff. It is cost-effective and patient friendly. If surgery is performed according to standardized method, it is well tolerated by patients and overwhelming majority has almost no limitations and no pain of their daily activities $24 \mathrm{hrs}$ after the procedure. It has helped the patient to return to her daily core of house hold activities where she plays a very important role in taking care of the family. In our study, 95\% patient was satisfied with the procedure and would recommend it to others. The day care surgery helped patient to return to their home same day without adding burden on their family members, early return to their daily chore of household activities especially in nuclear families and it also help them in reducing the cost of more hospital stay.

Counselling of the patients by surgeon, makes a world of difference to the patients and relatives, in accepting concept of day care surgery. A major concern of patient is post-operative care, especially in case of emergency, which has to be addressed with assurance from all concerned, in relation to the safety of the procedure with a good back up team in place.

Table 5: Comparison of duration of surgery and hospital stay in different studies.

\begin{tabular}{|lllll|}
\hline Authors & $\begin{array}{l}\text { No. of laparoscopic } \\
\text { hysterectomy cases }\end{array}$ & $\begin{array}{l}\text { Type of procedure } \\
\text { McClellan SN et al. 2007 }\end{array}$ & $\begin{array}{l}\text { Duration of surgery } \\
\text { (Mean) }\end{array}$ & $\begin{array}{l}\text { Total hospital stay } \\
\text { (Mean) }\end{array}$ \\
\hline Karaman Y et al. 2007 & 1120 & LSH & 156 minutes & 16.5 hours \\
\hline Theil JA. et al, 2006 & 224 & TLH / LAVH & 55 minutes & 48 hours. \\
\hline Morrison JE Jr et al. 2004 & 52 & TLH & 79 minutes & 5.9 hours \\
\hline Chou DC et al. 2000 & 30 & Modified CISH & 134 minutes & 11 hours, 37 minutes \\
\hline Present study & 200 & TLH & 115 minutes & 22.9 hours \\
\hline
\end{tabular}

\section{CONCLUSION}

These preliminary data suggests that day care laparoscopic hysterectomy is feasible, safe with greater efficacy; however the skill of the surgeon matters. With better understanding of the technique, the advent of better anaesthetic agent, increased surgical experience and patient awareness has helped day care surgery in to an art and which can be considered as a speciality.

Funding: No funding sources Conflict of interest: None declared

Ethical approval: The study was approved by the centre ethics committee

\section{REFERENCES}

1. Sutton C. Hysterectomy: a historical perspective. Baillieres Clin Obstet Gynaecol. 1997;11(1):1-22.

2. E. M. Thompson, H. M. L. Mathews, D. M. McAuley. Problems in day care surgery. Ulster Med J. 1991;60(2):176-82.

3. Wood C, Maber PJ. Laparoscopic hysterectomy. Baillieres Clin Obstet Gynaecol. 1997;11(1):111-36.

4. Thiel J, Gamelin A. Outpatient total laparoscopic hysterectomy. J Am Assoc Gynaecol Laparosc. 2003;10(4):481-3.
5. Chapron C, Dubuisson JB, Ansquer Y. Total laparoscopic hysterectomy: indications, results and complications. Ann N Y Acad Sci. 1997;828:341-51.

6. Hawe JA, Garry R. Laparoscopic hysterectomy. Semin Laparosc Surg. 1999;6(2):80-9.

7. Chapron CM, DubuissonJB, Ansquer Y. Is total laparoscopic hysterectomy a safe procedure? Hum Reprod. 1996;(11)110:2422-24.

8. Nicolas Chopin, Jean Marie Malaret, Marie-Christine Lafay-Pillet, Aldolphe Fotso, Herve Foulot, Charles Chapron. Total laparoscopic hysterectomy for benign uterine pathologies: obesity does not increase the risk of complications. Hum Reprod. 2009;24(12):305762.

9. Katherine A, O'Hanlan, Stacey Paris McCutcheon, John G. McCutcheon. Laparoscopic hysterectomy: impact of uterine size. J Minim Invasive Gynaecol. 2011;18(1):85-91.

10. Christopher CM. Ng, Bernard SM. Chern, Anthony YM. Siow. Retrospective study of the success rates and complications associated with total laparoscopic hysterectomy. J Obstet Gynaecol. 2007;33(1):512-8.

11. David J. Bonilla, Lindsay Mains, Janet Rice, Benjamin Crawford. Total laparoscopic hysterectomy: our 5 year experience (1998-2002). Ochsner J. 2010;10:8-12.

12. van Evert JS, Smeenk JM, Dijkhuizen FP, de Kruif JH, Kluivers KB. Laparoscopic sub-total 
hysterectomy versus laparoscopic total hysterectomy: a decade of experience. Gynaecol Surg. 2010;7:9-12.

13. Thiel JA, Kamencic H. Assessment of costs associated with outpatient total laparoscopic hysterectomy. J Obstet Gynaecol Can. 2006;28(9):794-8.

14. 1Morrison JE Jr, Jacobs VR. Outpatient laparoscopic hysterectomy in a rural ambulatory surgery center. J Am Assoc Gynaecol Laparosc. 2004 Aug;11(3):35964.

15. Kapoor Nisha, Manju Seema, Mittal Aruna, Gupta Meenakshi. Laparoscopic assisted vaginal hysterectomy: an effective alternative to conventional abdominal hysterectomy. J Obstet Gynaecol India. 2010 sept;60(5):429-35.

16. Holub Z, Jabor A, Sprongl L, Fischlová D, Urbánek S. Clinical outcome, inflammatory response and tissue trauma in total laparoscopic hysterectomy: comparison to laparoscopically-assisted vaginal hysterectomy. Ceska Gynaecol. 2002 Nov;67(6):31520 .

17. Karaman Y, Bingol B, Günenç Z. Prevention of complications in laparoscopic hysterectomy: experience with 1120 cases performed by a single surgeon. J Minim Invasive Gynaecol. 2007 JanFeb;14(1):78-84.

18. Payne TN, Dauterive FR. A comparison of total laparoscopic hysterectomy to robotically assisted hysterectomy: surgical outcome in community practice. J Minim Invasive Gynaecol. 2008;15:28691.

19. Chang WC, Lin WC, Hung YC. Pelvic adhesions in LAVH. Int J Gynaecol Obstet. 2006;94:145-6.

20. Taylor RH. Outpatient laparoscopic hysterectomy with discharge in 4 to 6 hours. J Am Assoc Gynaecol Laparosc. 1994 Aug;1(4, Part 2):S35.

21. Hoffman CP, Kennedy J, Borschel L, Burchette R, Kidd A. Laparoscopic hysterectomy: the Kaiser Permanente San Diego experience. J Minim Invasive Gynaecol. 2005 Jan-Feb;12(1):16-24.

22. Chou DC, Rosen DM, Cario GM, Carlton MA, Lam AM, Chapman M, et al. Home within 24 hours of laparoscopic hysterectomy. Aust N Z J Obstet Gynaecol. 2000 Feb;40(1):108.

23. McClellan SN, Hamilton B, Rettenmaier MA, Lopez $\mathrm{K}$, John $\mathrm{CR}$, Hu JC, et al. Individual physician experience with laparoscopic supracervical hysterectomy in a single outpatient setting. Surg Innov. 2007 Jun;14(2):102-6.

24. Lieng $M$, Istre $O$, Langebrekke $A$, Jungersen $M$, Busund B. Outpatient laparoscopic supracervical hysterectomy with assistance of the lap loop. J Minim Invasive Gynaecol. 2005 May-Jun;12(3):2904.

DOI: $10.5455 / 2320-1770 . i j r \operatorname{cog} 20140982$

Cite this article as: Thyagaraju C, Modi R.

Feasibility of total laparoscopic hysterectomy as a day care procedure. Int J Reprod Contracept Obstet Gynecol 2014;3:735-41. 